Available Online at SAINS TANAH Website: http://jurnal.uns.ac.id/tanah

SAINS TANAH - Journal of Soil Science and Agroclimatology, 16(1), 2019, 112-126

REVIEW ARTICLE

\title{
PHYSIOLOGY AND BIOCHEMISTRY OF FE EXCESS IN ACIDIC ASIAN SOILS ON CROP PLANTS
}

\author{
Sangita Dey, Saradia Kar, Preetom Regon, and Sanjib Kumar Panda* \\ Plant Biotechnology and Functional Genomics Laboratory, Department of Life Science and \\ Bioinformatics, Assam University, Silchar-788011 \\ Submitted : 2019-06-03 Accepted: 2019-06-29
}

\begin{abstract}
Proper transport of iron is very crucial for plant growth and development as it participates in various complex processes in plants like absorption, translocation, etc. It also acts as an important component for processes like photosynthesis and respiratory electron transport chain in mitochondria, chloroplast development, and chlorophyll biosynthesis. Asian soils suffer from iron toxic condition and that adversely affects the growth and yield of the plant. This review describes the importance of iron in plant growth and different strategies adopted by plants for iron uptake. It also focuses on different methods and approaches on how plant can cope against acidic soils.
\end{abstract}

Keywords: Iron excess, Iron homeostasis, Gene, Transcription factor

How to Cite: Dey, S., Kar, S., Regon, P., and Panda, S. K. (2019). Physiology and Biochemistry of Fe Excess in Acidic Asian Soils on Crop Plants. Sains Tanah Journal of Soil Science and Agroclimatology, 16(1): 112126 (doi: 10.20961/stjssa.v16i1.30456)

Permalink/DOI: http://dx.doi.org/10.20961/stjssa.v16i1.30456

\section{INTRODUCTION}

Iron is one of the most abundant element found in the earth's crust and due to its low solubility in aerobic environment, it is considered as the third most limiting nutrient for plant growth (Grotz \& Guerinot, 2006). Iron uptake in plants is an important physiological process governed by various complex homeostatic mechanisms in the plant, including absorption, translocation, and distribution of the iron within the entire plant system so that all the iron-dependent biological processes can actively participate in the plant growth and development (Römheld \& Schaaf, 2004). In higher plants, iron act as a key component for the biological processes like photosynthesis and respiratory electron transport chain in

* Corresponding Author:

Email:profskpanda73@gmail.com mitochondria as well as iron is associated with sulfate assimilation, hormone synthesis and in DNA synthesis and repair. However, its excess and deficiency can have harmful effects on plants. Excess free iron which is found in the low $\mathrm{pH}$ and high oxygen tension can affect the cell because of its high affinity to bind with oxygen leading to the generation of cytotoxic hydroxyl radicals via Fenton reaction (Connolly \& Guerinot, 2002; Becker \& Asch, 2005; Grotz \& Guerinot, 2006). While in alkaline and aerobic soils, low iron concentration is frequently found which leads to the Fe-deficiency symptoms in plants like chlorosis and necrosis leading to the damage to plant biomass and yield (Eroglu et al., 2016). Iron exists in two oxidation states $\mathrm{Fe}^{3+}$ and $\mathrm{Fe}^{2+}$ and their rate of absorption and toxicity differs significantly, $\mathrm{Fe}^{2+}$ is typically the highly toxic form of iron absorbed by the plants (Brumbarova et al., 2015; Li et al., 2015). 


$$
\begin{aligned}
& \mathrm{Fe}^{2+}+\mathrm{H}_{2} \mathrm{O}_{2}=\mathrm{Fe}^{3+}+\mathrm{HO}^{\cdot}+\mathrm{OH}^{-} \\
& \mathrm{Fe}^{3+}+\mathrm{H}_{2} \mathrm{O}_{2}=\mathrm{Fe}^{2+}+\mathrm{HOO}+\mathrm{H}^{+} \\
& \text {Large number of soil types can be }
\end{aligned}
$$
responsible in generating iron toxicity for the crops, like, acid sulfate soils, acid clay soil and peat soil (Becker \& Asch, 2005). Asia and Africa faces the problem of Fe toxicity in majority during their crop cultivation especially rice. This is due to the nutrient disorder on acid sulfate soils. It was reported previously that Fe toxicity prevailed mostly in young acid sulfate soil (Sahrawat, 2005; van Breemen, 1988). Large areas of tropical and sub-tropical regions of Asia are distributed with acid soils. Large quantity of $\mathrm{Fe}$ (II) rise in the soil content due to the unusual mineralization (Boruah \& Bharali, 2015). Due to the accumulation of Fe (II) from 500 to $5000 \mathrm{mg} \mathrm{kg}^{-1}$ soil brings $50-100 \%$ of yield loss (Sahrawat, 2005).

\section{Morphological changes}

The plant can respond to sub-optimal conditions by changing the root growth architecture such as altering the number, length, diameter of the root, and root hairs as root are the primary sensing site to come in contact with the stress condition, a process is known as stressed induced morphogenic response. Iron toxicity arrests the primary root growth by lowering the cell division and elongation which in turn inhibit the growth of the lateral root in newly grown roots resulting in the direct contact with excess Fe (Li et al., 2012; Li et al., 2015). Thus, this stress-induced morphogenic response of Root System Architecture (RSA) can help to restrict the absorption of excess iron in lower strata, still allowing the absorption of another essential nutrient in the other part of the root system and can prevent the plant from being in contact with more serious Fe toxicity. However, Feexcess has no such adverse effects in lateral root formation in the proximal roots which helps in the absorption of another essential nutrient despite being in contact with stress condition allowing the controlled acclimatization to nutritional stress (Heil \& Baldwin, 2002). In addition, the root gravitropism helps the root orientation whenever the root tip comes in the contact of excess iron and changes its direction away from the stress stimulus (Li et al., 2015; Wisniewska et al., 2006). Fe excess increases the abundance of ferritin protein which stores numerous Fe atoms in their central cavity. The major role of ferritin in specific areas like flowers and leaves is to protect against oxidative stress. However, the complete information is not available about the synthesis and function of ferritin in roots (Sudre et al., 2013). One of the major phenomena during the iron toxicity is the occurrence of dark brown spot (bronzing) which starts from the tip of the leaf and gradually expand towards the other part of the leaf as shown in Figure 3 (a-e) (Peng \& Yamauchi, 1993). Bronzing is also considered as a nutritional disorder which is extensively distributed in lowland areas (Tanaka \& Yoshida, 1970).

In contrast, to cope up with the Fedeficient condition, the plant can enlarge the root surface area. The iron content scarcity can trigger the formation of ectopic root hairs at the position normally occupied by the non-hair cells, this phenomenon helps in Fe uptake by increasing its absorptive surface area of the root (Schmidt et al., 2000). The length of primary roots and the number of the lateral roots increases under moderate low $\mathrm{Fe}$ condition while drastically decreases in the severe cases of low iron content (Gruber et al., 2013).

In legumes, there is a greater demand for iron needed for the symbiotic association with Nitrogen-fixing bacteria and for the synthesis of iron-containing protein like leghaemoglobin in the host. Iron plays an essential role in the synthesis of nitrogenase 
and cytochrome of the electron transport chain in bacteroids. Nodule formation takes place in case of iron deficient condition (Brear et al., 2013).

\section{Iron uptake strategies in plants}

Plant has developed two strategies for iron uptake i.e., strategy I (reduction) and strategy II (chelation) based mechanism for the uptake of iron under Fe-deficient condition. All non-graminaceous plants utilize strategy I to uptake iron. Upon iron deficiency, rhizosphere is acidified with the proton extrusion performed by P-type $\mathrm{H}^{+}$-ATPase, HA, followed by the reduction of $\mathrm{Fe}^{3+}$ to $\mathrm{Fe}^{2+}$ by the membrane-bound ferric reductase oxidase (FRO2) which is induced by iron deficiency in the root epidermis (Schmidt, 2006; Santi \& Schmidt, 2009; Connolly et al., 2003). Once ferric is reduced to ferrous, it is transported into the root by iron-regulated transporter 1
(IRT1), a member of the zinc-regulated transporter (ZRT), IRT like protein ZIP family. FIT (FER-Like Iron Deficiency Induced Transcription Factor regulates the expression of AHA2, FRO2, and IRT1. FRO genes are expressed variably at the tissue level, FRO2 is expressed in roots and however, FRO6 and FRO7 are specifically expressed in shoots (Jeong \& Guerinot, 2009; Mukherjee et al., 2006). FRO proteins are localized into different cellular compartments and are involved in different cellular functions signifying that the reduction-based iron transfer is not only limited to the root plasma membrane (Mukherjee et al., 2006; Jeong et al., 2008; Heazlewood et al., 2004). Hormones like ethylene, auxin, jasmonic acid (JA), cytokinin (CK), brassinosteroids (BR), abscisic acid (ABA) and nitric oxide (NO) plays a significant role in the Fe-deficient signaling (Brumbarova et al., 2015; Jeong \& Guerinot, 2009).

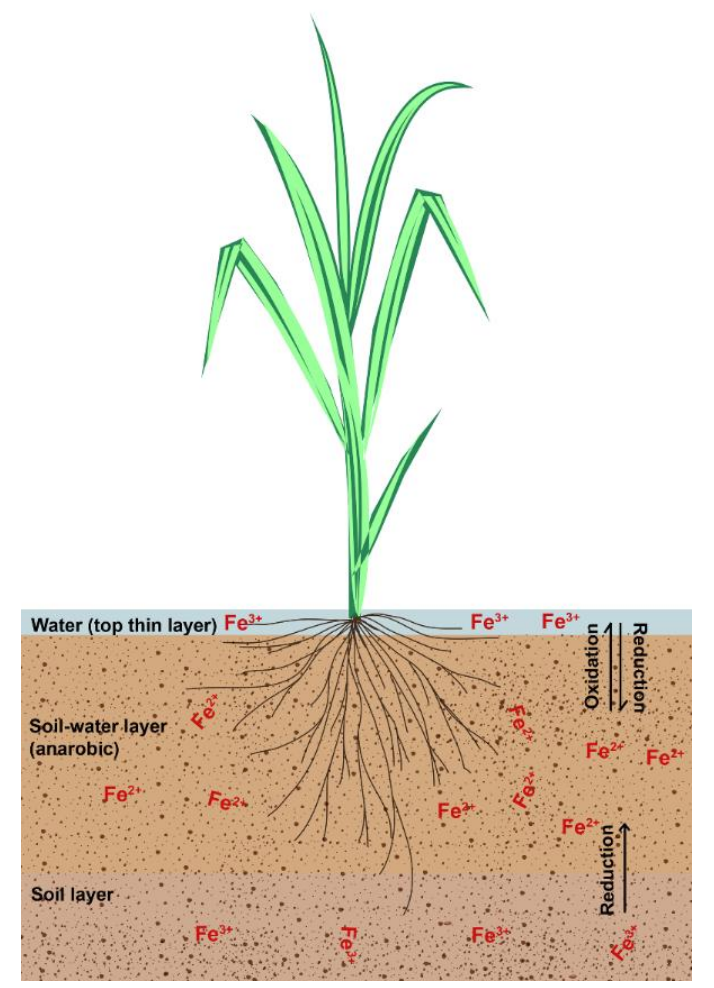

Figure 1. Distribution of Iron reduction in soil 


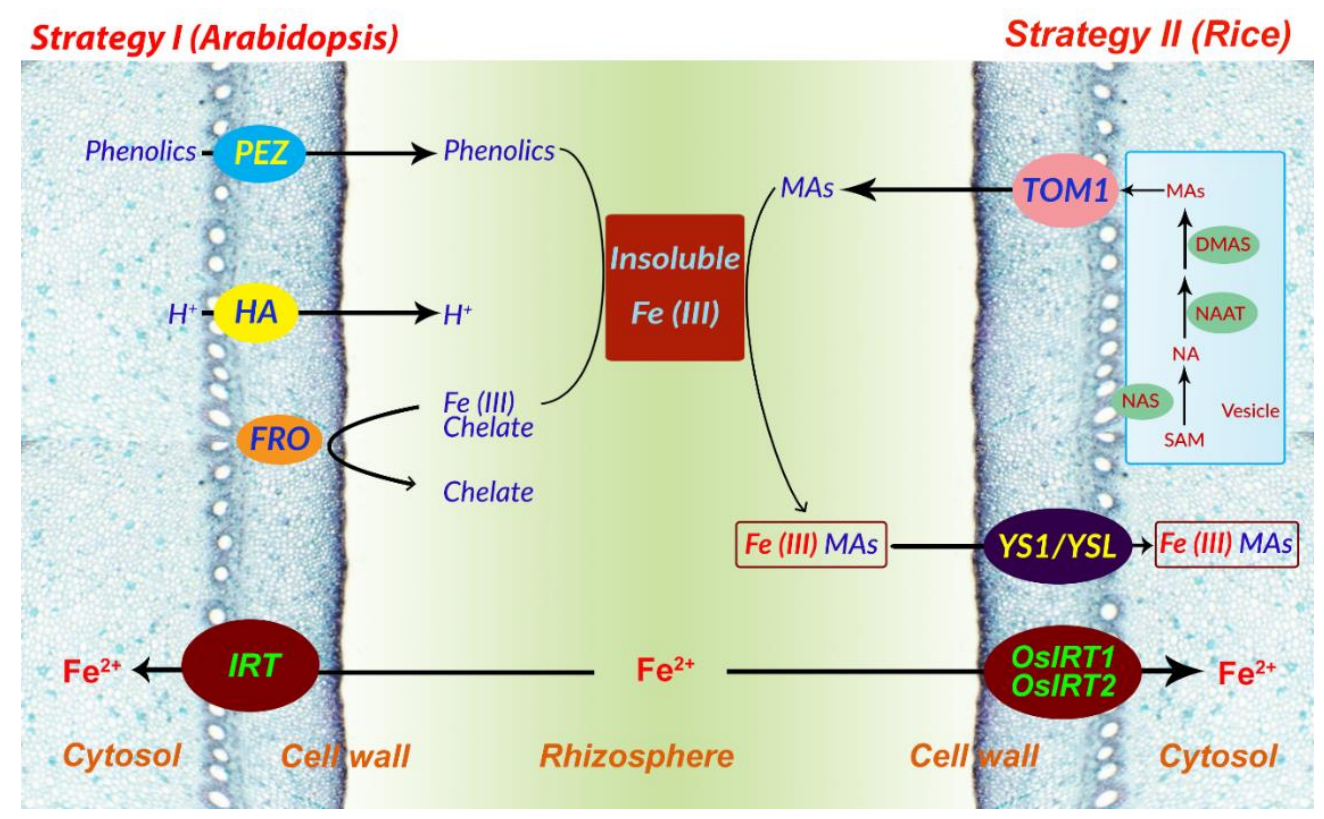

Figure 2. Schematic diagram showing the iron uptake strategies in plants

Strategy II dependent on the biosynthesis of mugineic acid. Till date, nine types of MAs have been identified which are synthesized through S-adenosyl-L-methionine pathway (Bashir et al., 2006; Shojima et al., 1990). Phytosiderophores 1 (PS) like TOM1 (transporter of mugineic acid family phytosiderophore) transport the mugineic acid to the root rhizospheres. Specific plasmalemma transporter proteins YS1 and YSL1 (Yellow stripe 1 and yellow stripe 1 like) then transport the $\mathrm{Fe}^{3+}$-PS complexes into the root cell (Römheld \& Marschne, 1986; Nozoye et al., 2011; Kobayashi \& Nishizawa, 2012). The S-adenosyl-L-methionine pathway includes three sequential steps of enzymatic reactions mediated by NAS-nicotianamine synthase, NAAT-nicotianamine aminotransferase and DMAS-deoxymugineic acid synthase which generates 2-deoxymugineic acid (DMA), the precursor of all other MAs. NAS and NAAT enzymes are localized on the membrane and inside of the vesicles respectively, suggesting that these vesicles are the site for MA biosynthesis (Takahashi et al., 1999; Higuchi et al., 1999).

Rice is considered as one of the exceptional cases, despite being a strategy II plant, it also possesses OsIRT1 and OsIRT2 that allows absorbing $\mathrm{Fe}^{2+}$ in addition to its strategy II mechanism based on the absorption of $\mathrm{Fe}^{3+}$ DMA complex by the OsYSL15 transporter (Bughio et al., 2002; Lee et al., 2009; Inoue et al., 2009; Ishimaru et al., 2006; Kar \& Panda, 2018). Although rice has a low content of ferric chelate reductase activity on its root surface, which suggests that it can directly take up $\mathrm{Fe}^{2+}$ which is found in abundant quantity in the submerged and anaerobic condition (Ishimaru et al., 2006). Recent studies have shown that soil microbial community which are influenced by root exudates can have impact on Fe acquisition (Jin et al., 2010). Under excessive Fe concentration, engages apoplastic and symplastic mechanism under Fe supply. However, the interception mechanism is not fully understood but about $90 \%$ of $\mathrm{Fe}$ is intercepted by root apoplast which is due to the alkalinization of the apoplastic $\mathrm{pH}$ (Kosegarten et al., 2004). The availability of $\mathrm{Fe}^{2+}$ is reduced in the apoplast, thus affecting both mobilities as well as the chemical stability of the ion and this alkalinizationin turn can be affected by ethylene (Staal et al., 2011). 
According to the earlier report, various hormones like ethylene, auxin and Nitric oxide (NO) plays a vital role in the cell wall adjustment in response to stress (Xiong et al., 2009; Zhu et al., 2013). $\mathrm{Fe}^{2+}$ can also be excluded from the root-cell membrane. Plants can seize $\mathrm{Fe}^{2+}$ in the root cell vacuoles and in multimeric protein ferritin. In Arabidopsis, the regulation of ferritin gene is expressed at the transcriptional level and involves $A B A$, Reactive Oxygen species (ROS) and ethylene-mediated regulatory pathways (Li et al., 2015; Briat et al., 2010). However, the signaling pathway leading to the induction of ferritin gene is neither dependent on $A B A$ nor on oxidative stress in African rice (Majerus et al., 2009).

\section{Iron translocation in plants}

Due to the high reactivity and low solubility of $\mathrm{Fe}$ in nature, its translocation inside the plant must be highly regulated with proper redox states of $\mathrm{Fe}^{3+}$ and $\mathrm{Fe}^{2+}$ forms and suitable chelating molecules (Hell \& Stephan, 2003). Various steps are involved in $\mathrm{Fe}$ translocation in plants, (a) symplastic transport through caspariasn stripes from the root tissues (b) xylem and phloem loading, transport and unloading, (c) xylem-phloem transfer, (d) symplastic movement towards the region of need and finally translocating from the source (Kim \& Guerinot, 2007). Localization of iron acquisition inside the plant tissue can be visualized with Perl's blue staining methods as shown in Figure 3 (f-g) (Roschzttardtz et al., 2013). Physiological and molecular studies have indicated few of the important chelators inside the plant body like MAs, nicotianamine, citrate (Aoyama et al., 2009; Takahashi et al., 2003; Brown \& Chaney, 1971).

FERRIC REDUCTASE DEFECTIVE 3 (FRD3) MATE efflux family protein; responsible for loading citrate into the xylem tissues. During plant growth and development iron also mediates the citrate release in the apoplastic region allowing the iron nutrition to be distributed in the tissues which are not connected through symplast (Durrett, Gassmann, \& Rogers, 2007; Rogers \& Guerinot, 2002). The mutation of FRD3 transporter results in the Fe localization to the central vascular cylinder of the roots and fails to transport to the aerial parts thus suggesting citrate plays a significant role in xylem Fe transport. OsFRDL1, an FRD3 like gene in Rice similar to Arabidopsis, which is specifically expressed in root pericycle cells encodes a citrate efflux required for efficient $\mathrm{Fe}$ translocation (Green \& Rogers, 2004; Yokosho at al., 2008).

PEZ1, another novel efflux named after its mutant phenotype, which has lower amounts of protocatechuic and caffeic acid in the xylem sap, are responsible for xylem loading of these phenolic compounds facilitating remobilization of the precipitated apoplasmic Fe inside the plant (Ishimaru et al., 2011). YSL family members are the influx transporter which is widely involved in $\mathrm{Fe}$ translocation. Maize YS1, the founding member of YSL family facilitates Fe(III)-DMA uptake from the rhizosphere and is induced both in roots and shoots in response to iron deficiency (Curie et al., 2001). YSL family members are also present in nongraminaceous plants but they do not synthesize MA, moreover, they are thought to be involved in translocation of metals chelated with nicotianamine (NA) (Curie et al., 2009). NA is the precursor and structural analog of MAs which chelates various metals and also synthesized by almost all plants. Rice, a strategy II plant comprises 18 YSL members (OsYSL1-18). Out of 18, OsYSL2 transports $\mathrm{Fe}(\mathrm{II})-\mathrm{NA}$ and $\mathrm{Mn}$ (II)-NA instead of Fe(III)-MAs and is responsible for long-distance transport to sink tissues including leaves and grains (Ishimaru et al., 2010; Koike et al., 2004). 

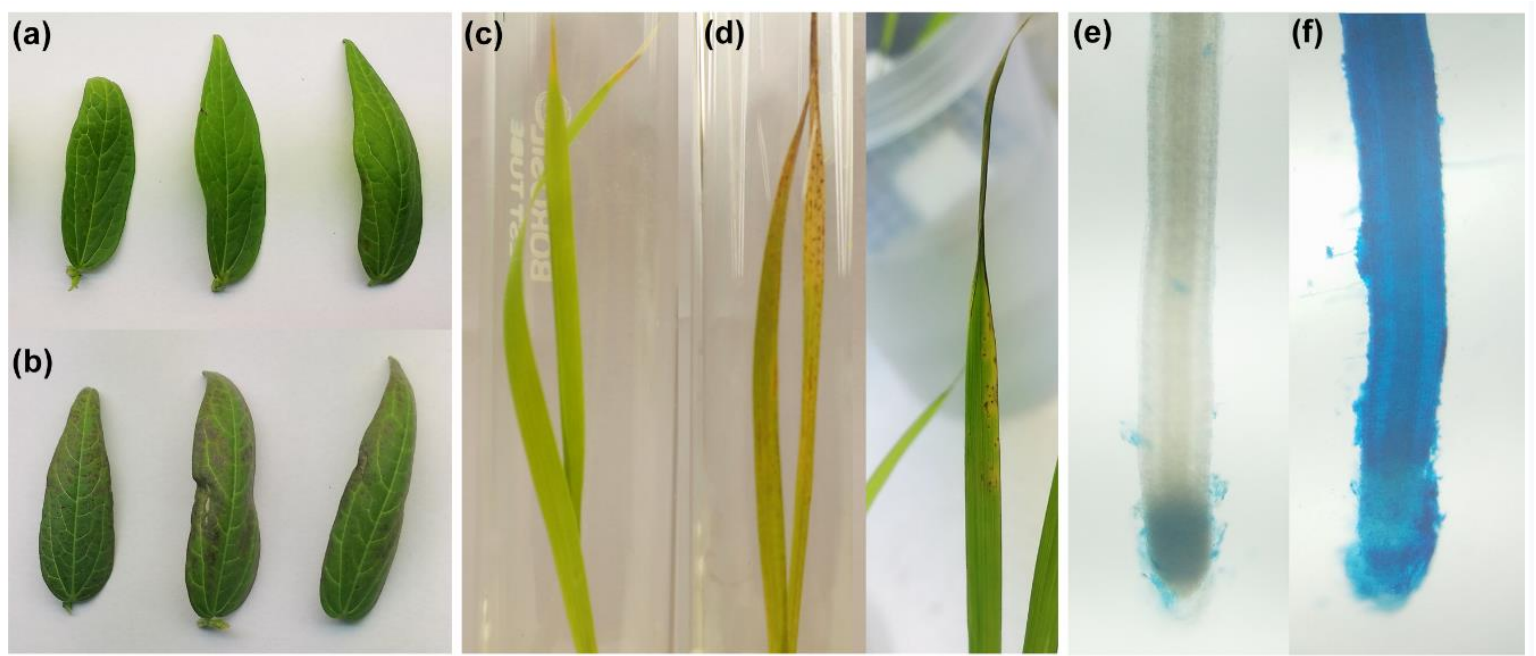

Figure 3. Representing occurrence of brown spot on leaf and uptake of iron using Perls staining method under iron toxic condition after 72 hours of stress. (a) Blackgram leaves in control condition, (b) Blackgram leaves in iron excess condition, (c) Rice leaves in control condition (experimental), (d) Rice leaves in iron excess condition (experimental), (e) Rice leaves in iron excess condition (natural), (f) Perls staining of root from rice plants under control condition, (g) Perls staining of root from rice plants under stressed condition.

OsYSL15 transports Fe(III)-DMA is responsible for the root absorption of Fe as well as Fe translocation for long-distance transport and seedling growth (Lee et al., 2009; Inoue et al., 2009). OsYSL18 is expressed in the reproductive parts of plants and play a role in fertilization and phloem Fe transport (Tsukamoto et al., 2009). In rice, TOM1, DMA efflux, and ferrous transporter OsIRT1 are expressed in vascular tissue which is not only involved in $\mathrm{Fe}$ uptake but also in $\mathrm{Fe}$ translocation (Nozoye et al., 2011).

\section{Fe-Acquisition at the Transcriptional Level}

FIT (FER LIKE IRON DEFICIENCY INDUCED TRANSCRIPTION FACTOR) which is homologous to the FER of Solanum lycopersicumis basic helix-loop-helix (bHLH) protein is the central transcriptional regulators of iron uptake (Bauer et al., 2004; Yuan et al., 2005). In iron deficient condition, expression of AHA2, FRO2, IRT1 is regulated by the FIT. FIT can form heterodimers with bHLH038, bHLH039, bHLH100, bHLH101, and collaborates to upregulate Fe-uptake genes (Yuan et al., 2008).
FIT activity is post-translationally regulated (Jakoby et al., 2004). Apart from the FIT factor, another bHLH transcriptional regulatory network POPEYE (PYE) is also involved in iron homeostasis. It has a role in the redistribution of the iron already imported. Experimentally, POPEYE is found to be involved in iron homeostasis by regulating genes such as FER4, FER3, NAS4, OPT3, NRAMP4, FRD3 and FRO3. Another gene firmly co-regulated with PYE is BRUTUS (BTS). Both PYE and BTS play an important role in response to iron deficient and interacts with ILR3 which is involved in iron sensing (Long et al., 2010). MYB10 and MYB72, member proteins of myeloblastosis (MYB) family of transcription factor, play a certain role in the $\mathrm{Fe}$ redistribution by regulating NICOTIANAMINE SYNTHASE 4 suggesting that MYB10 and MYB72 are the members of PYE regulatory networks (Palmer et al., 2013; Sivitz et al., 2012). However, the expression of MYB72 is regulated by FIT signifying transcriptional influence on Fe uptake and Fe redistribution which are highly interconnected. By regulating the expression of $ß$-glucosidase- 
encoding gene BGLU42, MYB72 mediates the production and exportation of phenolic compounds, thus serving as a link between Fe acquisition and induced systematic resistance to the pathogen (Van der Ent et al., 2008). ILR3, an additional bHLH protein is active in metal ion-mediated auxin sensing in Arabidopsis roots. ILR3 might participate in controlling metal homeostasis by regulating gene expression implicated in intracellular iron transport. Mutation of ILR3 may display altered Fe uptake in the deficient condition along with a decrease of 3 genes homologous to yeast Ccc1p (Rampey et al., 2006). Yeast Ccc1p and its homolog VIT1 participate in vacuolar iron influx. In addition to VIT1, various other proteins are also involved in the process of intracellular metal transport for the proper maintenance of iron homeostasis in plants. NRAMP3/4, disruption of the vacuolar iron transport; causes increased sensitivity in case of iron low conditions (Li et al., 2001; Kim et al., 2006).

\section{Fe-Dependent Transcription: Protein Level}

A variety of signaling molecules and plant hormones modulates the Fe deficiency in a positive manner and their action, therefore, is involved in Fe-uptake. It has been established that various phytohormones like ethylene and auxin play a crucial role in the uptake of Fe during Fe-deficient condition. FIT acts as a central element in the transcriptional regulation for other hormonal pathways. For the up-regulation of FIT, as well as FER (Meiser et al., 2011; García et al., 2010; Graziano \& Lamattina, 2007). Production of NO is essential; Ethylene and NO are required for the positive regulation of Fe-uptake. These two have an interconnected mechanism that includes corresponding influence on each other biosynthesis (García et al., 2010; Lingam et al., 2011). Ethylene has a positive effect on FIT transcription, because FIT can regulate its own gene transcription (Wang et al., 2007). NO also promotes FIT stability by preventing its degradation, which is proteasome-mediated (Van der Ent et al., 2008; Lingam et al., 2011; Sivitz et al., 2011). Auxin responses by acting upstream of ethylene and NO loop thus affecting positively to Fe-deficiency (Chen et al., 2010). GROWTH REGULATING FACTOR 11 (GRF11) is a part 160 of the root Fe-deficiency co-expression network encoding 14-3-3 protein, act downstream of NO 161 in promoting FIT transcription. As because FIT is also required for the up-regulation of GRF11, this regulation pattern is reciprocal acting through E-box elements in the GRF11 promoter. The gene expression of grf11 mutant and protein-protein interaction does not indicate the participation of GRF11 in the post-transcriptional regulation of FIT (J. L. Yang et al., 2013).

Experimental evidence suggests that plant hormone ethylene in dicot plants indicates a physiological connection between ethylene and iron deficiency signaling, ethylene is produced upon Fe deficiency (Li \& Li, 2004; Zuchi et al., 2009) ETHYLENE INSENSITIVE 3 (EIN3) AND ETHYLENE INSENSITIVE3 LIKE 1 (EIL1) are two members of a plant-specific transcription factor that are activated through ethylene signaling pathway. EIN3/EIL1 act for the reorganization of the photosystems to reduce the photo-oxidative damage. This interaction reduces the chances of FIT degradation and maintains its active state, promoting Fe uptake (Lingam et al., 2011). The mediator (MED) complex, serves as a site-specific transcription factor and RNA polymerase II, revealed to be a part of the Fedependent gene expression. MED16 loss-offunction plants are hypersensitive to $\mathrm{Fe}$ deficiency and low level of expression of FIT, FRO2 and IRT1. MED16 interacts with MED25 which in turn interacts with EIN3/EIL1. However, MED16 can directly interacts with FIT (Yang et al., 2014; Zhang et al., 2014). RNA 
polymerase II complex-acts upstream of FIT, IbbHLH genes, FRO2 and IRT1. Their effects can be seen in the few days of Fe-deficiency (Aksoy et al., 2013). Although the significant role of CPL1 as RNA polymerase II regulatory subunit is still debatable, it may be involved in the cotranscriptional mRNA processing due to the presence of double-stranded RNA binding domain (Goeres et al., 2007).

\section{The cope up mechanism of crop against acidic} soil

Various agronomic management has been made to cope with excess iron. Approaches like planting date, water management, ridge planting and most importantly pre-submergence of soils which are considered as cultural methods can be manipulated and applied to reduce the iron toxicity in crops. In addition to manual methodologies in controlling the acidity of soil, plant itself develops tolerance mechanisms to avoid metal stress under acidic condition (Ernst, 2006). At first step, some of the plants immobilize the metal itself by releasing root exudates. On the other hand, same exudates can help in chelation of metal helping its uptake under deficient condition. As every metal homeostasis is under control of specific genes, the alteration of the gene functions may lead to tolerance of these metallophytes (Mehes-Smith et al., 2013). As an iron toxicity tolerance, plants undergo enzymatic oxidation at the root surface forming root plaque as a first line of physical barrier. As a second line of defense, the antioxidant enzymes, like, Ascorbate peroxidase (APx), Peroxidase, Catalase, Superoxide dismutase (SOD), Glutathione reductase, are in continuous action reducing the oxidative stress in the plants (Mahender et al., 2019). Under iron deficiency, the plant localize additional $\mathrm{Fe}$ in the vacuole. Under necessary conditions, the Fe shall be transported from the vacuoles to other parts by transporters like VIT1, VIT2, PIC, NRAMP (Zhang et al., 2012; Kobayashi et al., 2005). Hence, under toxic condition, a combination of the cultivation of stresstolerant crops along with the efficient practice of cultural methods can help of minimize the stress (Sahrawat, 2005).

\section{CONCLUSION}

The findings available till date on iron uptake in acid soils and their homeostasis reveals new avenues for future investigation for the exploration of the Fe-uptake mechanism and also provide few unsolved questions which need an explanation for the proper understanding of iron homeostasis. The link between basic transcriptional machinery and Fe response- specific transcriptional factor has already been explained in case of $\mathrm{Fe}$ deficiency. One of the important void to be filled is in case of iron excess. Iron excess has its adverse effects on plant growth and reduces the total yield of the crop. However, a little is known about how the hormones play their role when plant roots come in contact with the Feexcess stress condition.

Understanding physiological and morphological response leads to the first step towards establishing the plant behavior under toxic or deficient conditions. It opens the door for breeding prospects where an "efficient Fe genotype" can be crossed with "inefficient Fe genotype" as explained by Nikolic \& Pavlovic (2018). Marker Assisted Selection (MAS) is one of the indirect methods of screening the desired genotypes through their morphological traits. This method can be used to bring genetic crop improvements with agronomic traits. In case of Iron stress, the traits shall include the tolerance mechanisms against both toxic and deficient state. The selected lines can be later transferred for field tests.

The molecular based $\mathrm{Fe}$ acquisition studies has made the interpretation of Strategy 
I and II of both dicot and monocot much clear. However, signaling studies under Fe stress responses is yet to be extended. In recent years much work has been done to understand the transcriptional regulation of genes related to metal homeostasis. However, their regulation shall have much more meaning if a sequential hypothesis or model can be established explaining how the regulation of the genes are interrelated. Explorations with new tools and technologies make our physiological and morphological explanations more authenticated. X-Ray fluorescence, X-Ray absorption spectroscopy, SEM, TEM, are few of the techniques which has been helping us to understand the localization of Fe (Sperotto et al., 2018). Under both, excess or deficient condition, we therefore, can go for either excluding excess $\mathrm{Fe}$ from the tissues, or developing biofortification strategies for crops. The Next Generation sequencing is another way to find out the non-targeted gene and allele discovery. These methods can also lead to arrange breeding programs along with new biotechnological interventions like oligo directed mutagenesis, reverse breeding, RNA directed DNA methylation, Crispr-cas9 which can help us understanding the tolerance mechanisms against iron stress.

\section{REFERENCES}

Aksoy, E., Jeong, I. S., \& Koiwa, H. (2013). Loss of Function of Arabidopsis C-Terminal Domain Phosphatase-Like1 Activates Iron Deficiency Responses at the Transcriptional Level. Plant Physiology, 161(1), 330-345.

Aoyama, T., Kobayashi, T., Takahashi, M., Nagasa, S., Usuda, K., Kakei, Y., ... Nishizawa, N. K. (2009). OsYSL18 is a Rice Iron(III)-Deoxymugineic Acid Transporter Specifically Expressed in Reproductive Organs and Phloem of Lamina Joints. Plant Molecular Biology, 70(6), 681-692.

Bashir, K., Inoue, H., Nagasaka, S., Takahashi, M., Nakanishi, H., Mori, S., \& Nishizawa,
N. K. (2006). Cloning and Characterization of Deoxymugineic Acid Synthase Genes from Graminaceous Plants. Journal of Biological Chemistry, 281(43), 3239532402.

Bauer, P., Thiel, T., Klatte, M., Bereczky, Z., Brumbarova, T., Hell, R., \& Grosse, I. (2004). Analysis of Sequence, Map Position, and Gene Expression Reveals Conserved Essential Genes for Iron Uptake in Arabidopsis and Tomato. Plant Physiology, 136(4), 4169-4183.

Becker, M., \& Asch, F. (2005). Iron Toxicity in Rice - Conditions and Management Concepts. Plant Nutrient and Soil Science, 168(4), 558-573.

Boruah, K. K., \& Bharali, A. (2015). Physiological Basis of Iron Toxicity and its Management in Crops. In A. L. Singh (Ed.), Recent Advances in Crop Physiology (Vol. 2, pp. 203-224). New Delhi, India: Daya Publishing House.

Brear, E. M., Day, D. A., \& Smith, P. M. (2013). Iron: an Essential Micronutrient for the Legume-Rhizobium Symbiosis. Frontiers in Plant Science, 4, 1-15. 10.3389/fpls.2013.00359

Briat, J. F., Ravet, K., Arnaud, N., Duc, C., Boucherez, J., Touraine, B., ... Gaymard, F. (2010). New Insights into Ferritin Synthesis and Function Highlight a Link Between Iron Homeostasis and Oxidative Stress in Plants. Annals of Botany, 105(5), 811-822.

Brown, J. C., \& Chaney, R. L. (1971). Effect of Iron on the Transport of Citrate into the Xylem of Soybeans and Tomatoes. Plant Physiology, 47, 836-840.

Brumbarova, T., Bauer, P., \& Ivanov, R. (2015). Molecular Mechanisms Governing Arabidopsis Iron Uptake. Trends in Plant Science, 20(2), 124-133.

Bughio, N., Yamaguchi, H., Nishizawa, N. K., Nakanishi, H., \& Mori, S. (2002). Cloning an Iron-Regulated Metal Transporter from Rice. Journal of Experimental Botany, 53(374), 1677-1682.

Chen, W. W., Yang, J. L., Qin, C., Jin, C. W., Mo, J. H., Ye, T., \& Zheng, S. J. (2010). Nitric Oxide Acts Downstream of Auxin to Trigger Root Ferric-Chelate Reductase 
Activity in Response to Iron Deficiency in Arabidopsis. Plant Physiology, 154(2), 810-819.

Connolly, E. L., Campbell, N. H., Grotz, N., Prichard, C. L., \& Guerinot, M. L. (2003). Overexpression of the FRO2 Ferric Chelate Reductase Confers Tolerance to Growth on Low Iron and Uncovers Posttranscriptional Control. Plant Physiology, 133(3), 1102-1110.

Connolly, E. L., \& Guerinot, M. L. (2002). Iron Stress in Plants. Genome Biology, 3(8), REVIEWS1024.

Curie, C., Cassin, G., Couch, D., Divol, F., Higuchi, K., Le Jean, M., ... Mari, S. (2009). Metal Movement within the Plant: Contribution of Nicotianamine and Yellow Stripe 1-like Transporters. Annals of Botany, 103(1), 1-11.

Curie, C., Panaviene, Z., Loulergue, C., Dellaporta, S. L., Briat, J. F., \& Walker, E. L. (2001). Maize Yellow Stripe1 Encodes a Membrane Protein Directly Involved in Fe(III) Uptake. Nature, 409(6818), 346349.

Durrett, T. P., Gassmann, W., \& Rogers, E. E. (2007). The FRD3-Mediated Efflux of Citrate into the Root Vasculature is Necessary for Efficient Iron Translocation. Plant Physiology, 144(1), 197-205.

Ernst, W. H. O. (2006). Evolution of Metal Tolerance in Higher Plants. Forest Snow and Landscape Research, 80(3), 251-274.

Eroglu, S., Meier, B., von Wirén, N., \& Peiter, E. (2016). The Vacuolar Manganese Transporter MTP8 Determines Tolerance to Iron De fi ciency-Induced Chlorosis. Plant Physiology, 170(2), 1030-1045.

García, M. J., Lucena, C., Romera, F. J., Alcántara, E., \& Pérez-Vicente, R. (2010). Ethylene and Nitric Oxide Involvement in the Up-Regulation of Key Genes Related to Iron Acquisition and Homeostasis in Arabidopsis. Journal of Experimental Botany, 61(14), 3885-3899.

Goeres, D. C., van Norman, J. M., Zhang, W., Fauver, N. A., Spencer, M. L., \& Sieburth, L. E. (2007). Components of the Arabidopsis mRNA Decapping Complex Are Required for Early Seedling Development. Plant Cell, 19(5), 1549-
1564.

Graziano, M., \& Lamattina, L. (2007). Nitric Oxide Accumulation is Required for Molecular and Physiological Responses to Iron Deficiency in Tomato Roots. Plant Journal, 52(5), 949-960.

Green, L. S., \& Rogers, E. E. (2004). FRD3 Controls Iron Localization in Arabidopsis. Plant Physiology, 136, 2523-2531.

Grotz, N., \& LouGuerinot, M. (2006). Molecular Aspects of $\mathrm{Cu}, \mathrm{Fe}$ and $\mathrm{Zn}$ Homeostasis in Plants. Biochimica et Biophysica Acta (BBA) - Molecular Cell Research, 1763(7), 595-608.

Gruber, B. D., Giehl, R. F. H., Friedel, S., \& von Wiren, N. (2013). Plasticity of the Arabidopsis Root System under Nutrient Deficiencies. Plant Physiology, 163, 161179.

Heazlewood, J. L., Tonti-Filippini, J. S., Gout, A. M., Day, D. A., Whelan, J., \& Millar, A. H. (2004). Experimental Analysis of the Arabidopsis Mitochondrial Proteome Highlights Signaling and Regulatory Components, Provides Assessment of Targeting Prediction Programs, and Indicates Plant-Specific Mitochondrial Proteins. Plant Cell, 16(1), 241-256.

Heil, M., \& Baldwin, I. T. (2002). Fitness Costs of Induced Resistance: Emerging Experimental Support for a Slippery Concept. Trends in Plant Science, 7(2), 61-67.

Hell, R., \& Stephan, U. W. (2003). Iron Uptake, Trafficking and Homeostasis in Plants. Planta, 216(4), 541-551.

Higuchi, K., Suzuki, K., Nakanishl, H., Yamaguchi, H., Nishizawa, N. K., \& Mori, S. (1999). Cloning of Nicotianamine Synthase Genes, Novel Genes Involved in the Biosynthesis of Phytosiderophores. Plant Physiology, 119(2), 471-480.

Inoue, H., Kobayashi, T., Nozoye, T., Takahashi, M., Kakei, Y., Suzuki, K., ... Nishizawa, N. K. (2009). Rice OsYSL15 is an Iron-Regulated Iron (III)-Deoxymugineic Acid Transporter Expressed in the Roots and is Essential for Iron Uptake in Early Growth of the Seedlings. Journal of Biological Chemistry, 284(6), 3470-3479.

Ishimaru, Y., Kakei, Y., Shimo, H., Bashir, K., 
Sato, Y., Sato, Y., ... Nishizawa, N. K. (2011). A Rice Phenolic Efflux Transporter is Essential for Solubilizing Precipitated Apoplasmic Iron in the Plant Stele. Journal of Biological Chemistry, 286(28), 2464924655.

Ishimaru, Y., Masuda, H., Bashir, K., Inoue, H., Tsukamoto, T., Takahashi, M., ... Nishizawa, N. K. (2010). Rice MetalNicotianamine Transporter, OsYSL2, is Required for the Long-Distance Transport of Iron and Manganese. Plant Journal, 62(3), 379-390.

Ishimaru, Y., Suzuki, M., Tsukamoto, T., Suzuki, K., Nakazono, M., Kobayashi, T., ... Nishizawa, N. K. (2006). Rice Plants take up Iron as an $\mathrm{Fe} 3+-$ phytosiderophore and as Fe2+. Plant Journal, 45(3), 335-346.

Jakoby, M., Wang, H. Y., Reidt, W., Weisshaar, B., \& Bauer, P. (2004). FRU (BHLH029) is Required for Induction of Iron Mobilization Genes in Arabidopsis Thaliana. FEBS Letter, 577(3), 528-534.

Jeong, J., Cohu, C., Kerkeb, L., Pilon, M., Connolly, E. L., \& Guerinot, M. L. (2008). Chloroplast $\mathrm{Fe}(\mathrm{III})$ Chelate Reductase Activity is Essential for Seedling Viability under Iron Limiting Conditions. Proceeding of the National Academy of Science of the United State of America, 105(30), 10619-10624.

Jeong, J., \& Guerinot, M. L. (2009). Homing in on Iron Homeostasis in Plants. Trends in Plant Science, 14(5), 280-285.

Jin, C. W., Li, G. X., Yu, X. H., \& Zheng, S. J. (2010). Plant Fe Status Affects the Composition of Siderophore-Secreting Microbes in the Rhizosphere. Annals of Botany, 105(5), 835-841.

Kar, S., \& Panda, S. K. (2018). Iron Homeostasis in Rice: Deficit and Excess Sciences. In Proceedings of the National Academy of Sciences, India - Section B: Biological Sciences (pp. 1-9).

Kim, S. A., \& Guerinot, M. L. (2007). Mining Iron: Iron Uptake and Transport in Plants. FEBS Letter, 581(12), 2273-2280.

Kim, S. A., Punshon, T., Lanzirotti, A., Li, L., Alonso, J. M., Ecker, J. R., ... Guerinot, M. L. (2006). Localization of Iron in Arabidopsis Seed Requires the Vacuolar
Membrane Transporter VIT1. Science, 314(5803), 1295-1298.

Kobayashi, T., \& Nishizawa, N. K. (2012). Iron Uptake, Translocation, and Regulation in Higher Plants. Annual Review of Plant Biology, 63, 131-152.

Kobayashi, T., Suzuki, M., Inoue, H., Itai, R. N., Takahashi, M., Nakanishi, H., ... Nishizawa, N. K. (2005). Expression of Iron-Acquisition-Related Genes in IronDeficient Rice is Co-Ordinately Induced by Partially Conserved Iron-DeficiencyResponsive Elements. Journal of Experimental Botany, 56(415), 13051316.

Koike, S., Inoue, H., Mizuno, D., Takahashi, M., Nakanishi, H., Mori, S., \& Nishizawa, N. K. (2004). OsYSL2 is a Rice MetalNicotianamine Transporter that is Regulated by iron and Expressed in the Phloem. Plant Journal, 39(3), 415-424.

Kosegarten, H., Hoffmann, B., Rroco, E., Grolig, F., Glüsenkamp, K. H., \& Mengel, K. (2004). Apoplastic $\mathrm{pH}$ and Felll Reduction in Young Sunflower (Helianthus annuus) Roots. Physiologia Plantarum, 122(1), 95106.

Lee, S., Chiecko, J. C., Kim, S. A., Walker, E. L., Lee, Y., Guerinot, M. L., \& An, G. (2009). Disruption of OsYSL15 Leads to Iron Inefficiency in Rice Plants. Plant Physiology, 150, 786-800.

Li, G., Song, H., Li, B., Kronzucker, H. J., \& Shi, W. (2015). Auxin Resistant1 and PINFORMED2 Protect Lateral Root Formation in Arabidopsis under Iron Stress. Plant Physiology, 169, 2608-2623.

Li, G., Xu, W., Kronzucker, H. J., \& Shi, W. (2015). Ethylene is Critical to the Maintenance of Primary Root Growth and Fe Homeostasis under $\mathrm{Fe}$ Stress in Arabidopsis. Journal of Experimental Botany, 66(7), 2041-2054.

Li, L., Chen, O. S., McVey Ward, D., \& Kaplan, J. (2001). CCC1 is a Transporter that Mediates Vacuolar Iron Storage in Yeast. Journal of Biological Chemistry, 276(31), 29515-29519.

Li, X., \& Li, C. (2004). Is Ethylene Involved in Regulation of Root Ferric Reductase Activity of Dicotyledonous Species under 
Iron Deficiency? Plant and Soil, 261(1-2), 147-153.

Li, X., Ma, H., Jia, P., Wang, J., Jia, L., Zhang, T., ... Wei, X. (2012). Responses of Seedling Growth and Antioxidant Activity to Excess Iron and Copper in Triticumaestivum L. Ecotoxicology and Environment Safety, 86, 47-53.

Lingam, S., Mohrbacher, J., Brumbarova, T., Potuschak, T., Fink-Straube, C., Blondet, E., ... Bauer, P. (2011). Interaction between the bHLH Transcription Factor FIT and ETHYLENE INSENSITIVE3/ETHYLENE INSENSITIVE3LIKE1 Reveals Molecular Linkage between the Regulation of Iron Acquisition and Ethylene Signaling in Arabidopsis. Plant Cell, 23(5), 1815-1829.

Long, T. A., Tsukagoshi, H., Busch, W., Lahner, B., Salt, D. E., \& Benfey, P. N. (2010). The bHLH Transcription Factor POPEYE Regulates Response to Iron Deficiency in Arabidopsis Roots. Plant Cell, 22, 22192236.

Mahender, A., Swamy, B. P. M., Anandan, A., \& Ali, J. (2019). Tolerance if Iron-Deficient and Toxic Soil Condition in Rice. Plants, 8(2), 1-34.

Majerus, V., Bertin, P., \& Lutts, S. (2009). Abscisic Acid and Oxidative Stress Implications in Overall Ferritin Synthe. Plant and Soil, 324, 253-265.

Mehes-Smith, M., Nkongolo, K., \& Cholewa, E. (2013). Coping Mechanisms of Plants to Metal Contaminated Soil. In S. Silvern \& S. Young (Eds.), Environmental Change and Sustainability (pp. 53-90). London, UK: IntechOpen.

Meiser, J., Lingam, S., \& Bauer, P. (2011). Posttranslational Regulation of the Iron Deficiency Basic Helix-Loop-Helix Transcription Factor FIT Is Affected by Iron and Nitric Oxide. Plant Physiology, 157(4), 2154-2166.

Mukherjee, I., Campbell, N. H., Ash, J. S., \& Connolly, E. L. (2006). Expression Profiling of the Arabidopsis Ferric Chelate Reductase (FRO) Gene Family Reveals Differential Regulation by Iron and Copper. Planta, 223(6), 1178-1190.

Nikolic, M., \& Pavlovic, J. (2018). Plant
Responses to Iron Deficiency and Toxicity and Iron Use Efficiency in Plants. In M. A. Hossain, T. Kamiya, D. Burritt, L. S. P. Tran, \& T. Fujiwara (Eds.), Plant Micronutrient Use Efficiency Molecular and Genomic Perspectives in Crop Plants (pp. 55-69). Massachusetts, USA: Academic Press.

Nozoye, T., Nagasaka, S., Kobayashi, T., Takahashi, M., Sato, Y., Sato, Y., ... Nishizawa, N. K. (2011). Phytosiderophore Efflux Transporters are Crucial for Iron Acquisition in Graminaceous Plants. Journal of Biological Chemistry, 286(7), 5446-5454.

Palmer, C. M., Hindt, M. N., Schmidt, H., Clemens, S., \& Guerinot, M. L. (2013). MYB10 and MYB72 are Required for Growth under Iron-Limiting Conditions. PLoS Genetic, 9(11). 10.1371/journal.pgen.1003953

Peng, X. X., \& Yamauchi, M. (1993). Ethylene Production in Rice Bronzing Leaves Induced by Ferrous Iron. Plant and Soil, 149(2), 227-234.

Rampey, R. A., Woodward, A. W., Hobbs, B. N., Tierney, M. P., Lahner, B., Salt, D. E., \& Bartel, B. (2006). An Arabidopsis Basic Helix-Loop-Helix Leucine Zipper Protein Modulates Metal Homeostasis and Auxin Conjugate Responsiveness. Genetics, 174(4), 1841-1857.

Rogers, E. E., \& Guerinot, M. L. (2002). FRD3, a Member of the Multidrug and Toxin Efflux Family, Controls Iron Deficiency Responses in Arabidopsis. Plant Cell, 14(8), 1787-1799.

Römheld, V., \& Marschne, H. (1986). Evidence for a specific uptake system for iron phytosiderophores in roots of grasses. Plant Physiology, 80(1), 175-180.

Römheld, V., \& Schaaf, G. (2004). Iron Transport in Plants: Future Research in View of a Plant Nutritionist and a Molecular Biologist. Soil Science and Plant Nutrition, 50(7), 1003-1012.

Roschzttardtz, H., Conéjéro, G., Divol, F., Alcon, C., Verdeil, J. L., Curie, C., \& Mari, S. (2013). New Insights into Fe Localization in Plant Tissues. Frontiers in Plant Science, 4(350), 1-11.

Sahrawat, K. L. (2005). Iron Toxicity in Wetland 
Rice and the Role of Other Nutrients. Journal of Plant Nutrition, 27(8), 14711504.

Santi, S., \& Schmidt, W. (2009). Dissecting Iron Deficiency-Induced Proton Extrusion in Arabidopsis Roots. New Phytologist, 183(4), 1072-1084.

Schmidt, W. (2006). Iron Stress Responses in Roots of Strategy I Plant. In L. L. Barton \& J. Abadia (Eds.), Iron Nutrition in Plants and Rhizospheric Microorganisms. Switzerland: Springer, Cham.

Schmidt, W., Tittel, J., \& Schikora, A. (2000). Role of Hormones in the Induction of Iron Deficiency Responses in Arabidopsis Roots. Plant Physiology, 122, 1109-1118.

Shojima, S., Nishizawa, N. K., Fushiya, S., Nozoe, S., Irifune, T., \& Mori, S. (1990). Biosynthesis of Phytosiderophores. Plant Physiology, 93, 1497-1503.

Sivitz, A. B., Hermand, V., Curie, C., \& Vert, G. (2012). Arabidopsis bHLH100 and bHLH101 Control Iron Homeostasis via a FIT-Independent Pathway. PLos One, 7(9). 10.1371/journal.pone.0044843.

Sivitz, A., Grinvalds, C., Barberon, M., Curie, C., \& Vert, G. (2011). Proteasome-Mediated Turnover of the Transcriptional Activator FIT is Required for Plant Iron-Deficiency Responses. Plant Journal, 66(6), 10441052.

Sperotto, R. A., Menguer, P. K., \& Ricachenevsky, F. K. (2018). Molecular Bases of Iron Accumulation Towards the Development of Iron-Enriched Crops. In M. A. Hossain, T. Kamiya, D. J. Burritt, L. S. P. Tran, \& T. Fujiwara (Eds.), Plant Micronutrient Use Efficiency Molecular and Genomic Perspectives in Crop Plants (pp. 17-54). Massachusetts, USA: Academic Press.

Staal, M., De Cnodder, T., Simon, D., Vandenbussche, F., Van der Straeten, D., Verbelen, J. P., ... Vissenberg, K. (2011). Apoplastic Alkalinization is Instrumental for the Inhibition of Cell Elongation in the Arabidopsis Root by the Ethylene Precursor 1-Aminocyclopropane-1Carboxylic Acid. Plant Physiology, 155(4), 2049-2055.

Sudre, D., Gutierrez-Carbonell, E., Lattanzio, G.,
Rellán-Álvarez, R., Gaymard, F., Wohlgemuth, G., ... Briat, J. F. (2013). Iron-Dependent Modifications of the Flower Transcriptome, Proteome, Metabolome, and Hormonal Content in an Arabidopsis Ferritin Mutant. Journal of Experimental Botany, 64(10), 2665-2688.

Takahashi, M., Terada, Y., Nakai, I., Nakanishi, H., Yoshimura, E., Mori, S., \& Nishizawa, N. K. (2003). Role of Nicotianamine in the Intracellular Delivery of Metals and Plant Reproductive Developmen. Plant Cell, 15(6), 1263-1280.

Takahashi, M., Yamaguchi, H., Nakanishi, H., Shioiri, T., Nishizawa, N. K., \& Mori, S. (1999). Cloning Two Genes for Nicotianamine Aminotransferase, a Critical Enzyme in Iron Acquisition (Strategy II) in Graminaceous Plants. Plant Physiology, 121(3), 947-956.

Tanaka, A., \& Yoshida, S. (1970). Nutritional Disorder of Rice Plant in Asia. Los Banos, Philippines: IRRI Technical Bull.

Tsukamoto, T., Nakanishi, H., Uchida, H., Watanabe, S., Matsuhashi, S., Mori, S., \& Nishizawa, N. K. (2009). Fe Translocation in Barley as Monitored By a PositronEmitting Tracer Imaging System (Petis): Evidence For The Direct Translocation of Fe from Roots to Young Leaves Via Phloem. Plant and Cell Physiology, 50(1), 48-57.

van Breemen, N. (1988). Effects of Seasonal Redox Processes Involving iron on the Chemistry of Periodically Reduced Soils. In J. W. Stucki, B. A. Goodman, \& U. Schwertmann (Eds.), Iron in Soils and Clay Minerals (Vol. 217, pp. 797-809). Switzerland: Springer Nature.

Van der Ent, S., Verhagen, B. W., Van Doorn, R., Bakker, D., Verlaan, M. G., Pel, M. J., ... Pieterse, C. M. (2008). MYB72 Is Required in Early Signaling Steps of RhizobacteriaInduced Systemic Resistance in Arabidopsis. Plant Physiology, 146(3), 1293-1304.

Wang, H. Y., Klatte, M., Jakoby, M., Bäumlein, H., Weisshaar, B., \& Bauer, P. (2007). Iron Deficiency-Mediated Stress Regulation of Four Subgroup Ib BHLH Genes in Arabidopsis thaliana. Planta, 226(4), 897- 
908.

Wisniewska, J., Xu, J., Seifertová, D., Brewer, P. B., Ruzicka, K., Blilou, I., ... Friml, J. (2006). Polar PIN Localization Directs Auxin Flow in Plants. Science, 312(5775), $883 \mathrm{p}$.

Xiong, J., An, L., Lu, H., \& Zhu, C. (2009). Exogenous Nitric Oxide Enhances Cadmium Tolerance of Rice by Increasing Pectin and Hemicellulose Contents in Root Cell Wall. Planta, 230(4), 755-765.

Yang, J. L., Chen, W. W., Chen, L. Q., Qin, C., Jin, C. W., Shi, Y. Z., \& Zheng, J. S. (2013). The 14-3-3 protein GENERAL REGULATORY FACTOR11 (GRF11) Acts Downstream of Nitric Oxide to Regulate Iron Acquisition in Arabidopsis thaliana. New Phytologist, 197(3), 815-824.

Yang, Y., Ou, B., Zhang, J., Si, W., Gu, H., Qin, G., \& Qu, L. J. (2014). The Arabidopsis Mediator Subunit MED16 Regulates Iron Homeostasis by Associating with EIN3/EIL1 Through Subunit MED25. Plant Journal, 77(6), 838-851.

Yokosho, K., Yamaji, N., Ueno, D., Mitani, N., \& Ma, J. F. (2008). OsFRDL1 is a Citrate Transporter Required for Efficient Translocation of Iron in Rice. Plant Physiology, 149, 297-305.

Yuan, Y., Wu, H., Wang, N., Li, J., Zhao, W., Du, J., ... Ling, H. Q. (2008). FIT Interacts with AtbHLH38 and AtbHLH39 in Regulating Iron Uptake Gene Expression for iron Homeostasis in Arabidopsis. Cell
Research, 18(3), 385-397.

Yuan, Y. X., Zhang, J., Wang, D. W., \& Ling, H. Q. (2005). AtbHLH29 of Arabidopsis thaliana is a Functional Ortholog of Tomato FER Involved in Controlling Iron Acquisition in Strategy I Plants. Cell Research, 15(8), 613-621.

Zhang, Y., Wu, H., Wang, N., Fan, H., Chen, C., Cui, Y., ... Ling, H. Q. (2014). Mediator Subunit 16 Functions in the Regulation of Iron Uptake Gene Expression in Arabidopsis. New Phytologist, 203(3), 770-783.

Zhang, Y., Xu, Y. H., Yi, H. Y., \& Gong, J. M. (2012). Vacuolar Membrane Transporters OsVIT1 and OsVIT2 Modulate iron Translocation between Flag Leaves and Seeds in Rice. Plant Journal, 72(2), 400410.

Zhu, X. F., Wang, Z. W., Dong, F., Lei, G. J., Shi, Y. Z., Li, G. X., \& Zheng, S. J. (2013). Exogenous Auxin Alleviates Cadmium Toxicity in Arabidopsis thaliana by Stimulating Synthesis of Hemicellulose 1 and Increasing the Cadmium Fixation Capacity of Root Cell Walls. Journal of Hazard Materials, 263(2), 398-403. https://doi.org/10.1016/j.jhazmat.2013. 09.018

Zuchi, S., Cesco, S., Varanini, Z., Pinton, R., \& Astolfi, S. (2009). Sulphur Deprivation Limits Fe-Deficiency Responses in Tomato Plants. Planta, 230(1), 85-94. 


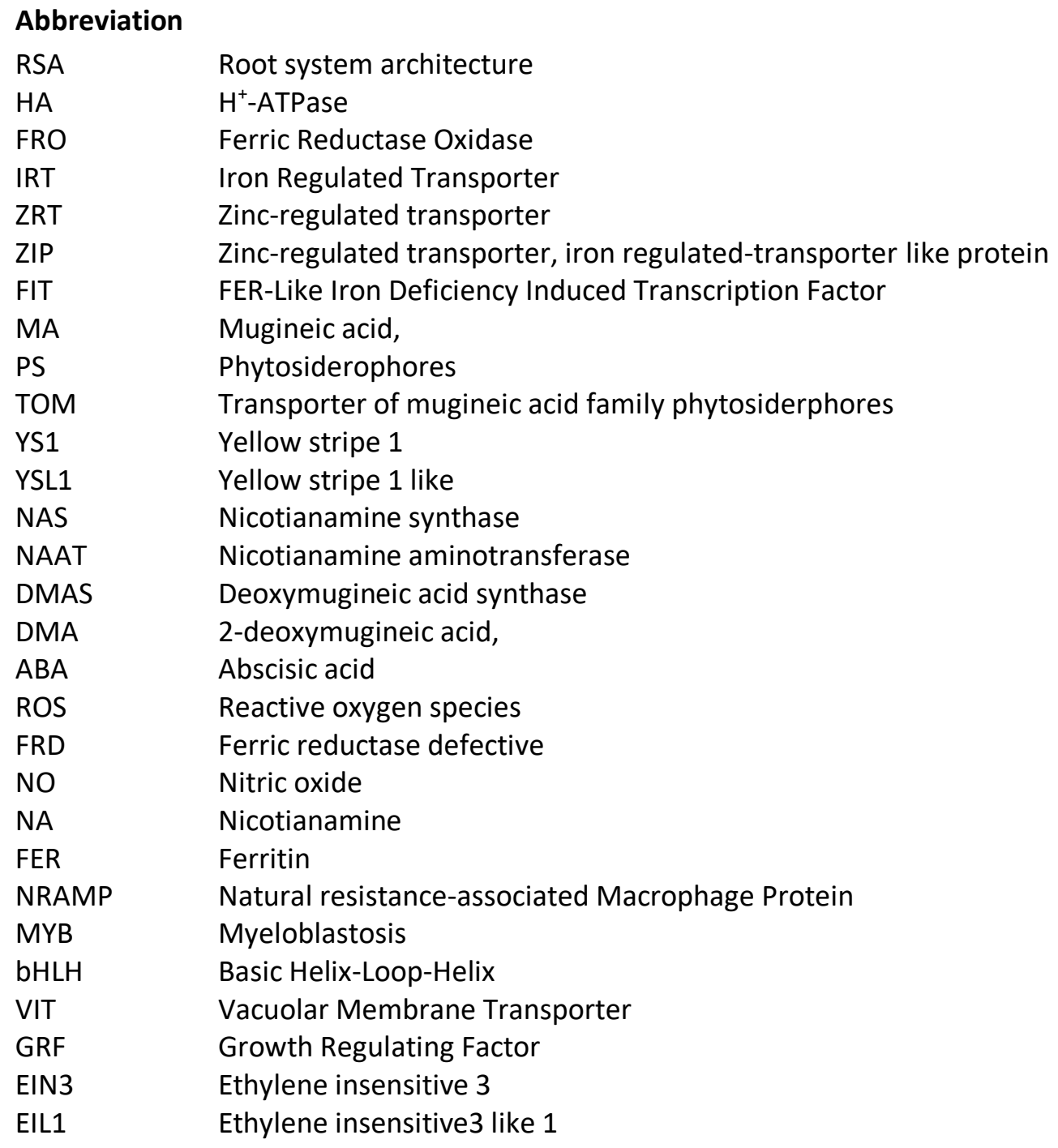

